\title{
DEVELOPMENT OF A FORCE MEASUREMENT DEVICE FOR LOWER-BODY MUSCULAR STRENGTH MEASURING OF SKATERS
}

\author{
DONG KI KIM \\ Center for Mass \& Force, KRISS, 209 Gajeong-Ro, \\ Yuseong-Gu, Daejeon 305-340, Republic of Korea \\ kdk2880@naver.com \\ JEONG TAE LEE* \\ Center for Mass \& Force, KRISS, 209 Gajeong-Ro, \\ Yuseong-Gu, Daejeon 305-340, Republic of Korea \\ jtlee@kriss.com
}

\begin{abstract}
This paper presents a force measurement system that can measure a lower-body muscular strength of skaters. The precise measurement and analysis of the left and right lower-body strength of skaters is necessary, because a left/right lower-body strength balance is helpful to improve the athletes' performance and to protect them from injury. The system is constructed with a skate sliding board, a couple of sensor-units with load cell, indicator and control box, guard, force pad, and support bracket. The developed force measurement system is calibrated by the calibration setup, and the uncertainty of the force sensing unit on the left is within $0.087 \%$ and the uncertainty of the force sensing unit on the right is within $0.109 \%$. In order to check the feasibility of the developed measurement device, a kinematic analysis is conducted with skater. As a result, the subject shows the deviation of left and right of $12.1 \mathrm{~N}$ with respect to average strength and $39.1 \mathrm{~N}$ with respect to the maximum strength. This evaluation results are reliable enough to make it possible to measure a lower-body muscular strength of skaters. The use of this measurement system will be expected to correct the posture of skaters and record the sports dynamics data for each athlete. It is believed that through the development of this equipment, skaters in elementary, middle, high schools, colleges, and the professional level have the systematic training to compete with world-class skaters.
\end{abstract}

Keywords: Skating; balance training; force measurement; shear beam load cell.

\section{Introduction}

Every muscles of the human body were sorted into a flexor muscle and an extensor muscle. The flexor muscle is a muscle that works for contraction of a body part, and the extensor muscle is a muscle that works to extend or straighten a body part, effectively enlarging the angle between body parts. The extensor muscle such as quadriceps femoris

This is an Open Access article published by World Scientific Publishing Company. It is distributed under the terms of the Creative Commons Attribution 3.0 (CC-BY) License. Further distribution of this work is permitted, provided the original work is properly cited.

${ }^{*}$ Corresponding author 
muscle is important for ice skating because a strong lateral pushing force of the lower body is needed during ice skating. The skating is also locomotion, but the movement of skating is different from running and walking [1]. During ice skating, the direction of movement of the lower body does not correspond with the moving direction, while the direction of movement of the lower body and the moving direction is same when the running and walking. In order to strengthen the quadriceps femoris muscle for ice skating, some sliding devices have been developed. Louis Keppler proposed some exercising apparatuses for a skater or similar athlete [2, 3]. However, proposed exercising apparatuses cannot measure the strength of the lower body to push to the lateral direction. Balance of lower limb muscle strength is an important factor to improve record [4]. The balance of the left/right lower-body strength is helpful not only to improve the athletes' performance but also to protect them from injury. Hence, the precise measurement system to measure and analyze the left and right lower-body strength of skaters is necessary.

In this paper, we present a force measurement system that can measure a lower-body muscular strength of skaters. The system is made up of skate sliding board and force sensing unit with strain-gauge type load cell. In order to check the feasibility of the developed measurement device, a kinematic analysis is conducted with three subjects who are skaters.

\section{Design and Fabrication}

The purpose of this study was to develop a force measurement system for measuring the force of the left and right low body when training speed skating. It is able to accurately measure and analyze the value of the maximum force by attaching strain gauges to the part where the force is applied and the deflection is generated. Fig. 1 shows the schematic design of the whole force measurement system with force sensing unit, skate sliding board, safety bars, and indicator. The measuring device is designed to establish a force measuring sensor at a position where force is transmitted, and it is designed to transmit the force to the sensor unit directly. Further, it is also designed to mount the safety sponge for shock absorption for the force sensor support portion, and the repulsive force that is redelivered to subject is decreased, and is designed to be able to prevent injury prevention. The force sensing unit is located in the central position of the safety bars, and the indicator that can convert the magnitude of the force to a numerical value $(\mathrm{N})$ are installed on the outer surface of the safety bar. Two compression strain gauges and two tensile strain gauges are connected to the Wheatstone bridge circuit symmetrically.

Fig. 2 presents the schematic design of the force sensing unit with load cell. The system is constructed with a skate sliding board, a couple of sensor-units with load cell, indicator and control box, guard, force pad, and support bracket. The skate sliding board is fabricated with polyethylene which has low coefficient of friction. Right and left sensor-units are located on the slide board, and the shear beam type load-cells that have a capacity of $1500 \mathrm{~N}$ are used for each sensor-unit. The indicator and the control box are installed on the back of the right side of the slide board, and the connector is installed to 
allow transfer data to the computer. The guard is a supporting unit for training and measuring the strength of the subjects. It makes the subjects keep separation of the sliding board. The force pad is in contact with the side surface of the outer legs, and the hard sponge on the force pad used for safe measurement. Support Bracket is installed on the guard to integrate the load cell and force pad with system.

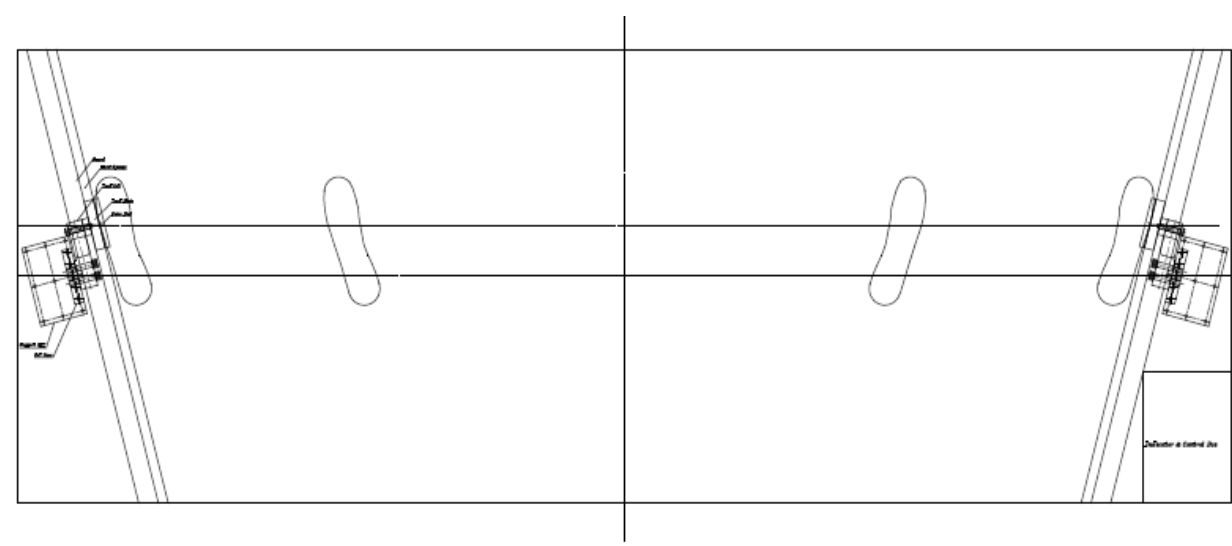

Skate Force Measurement System

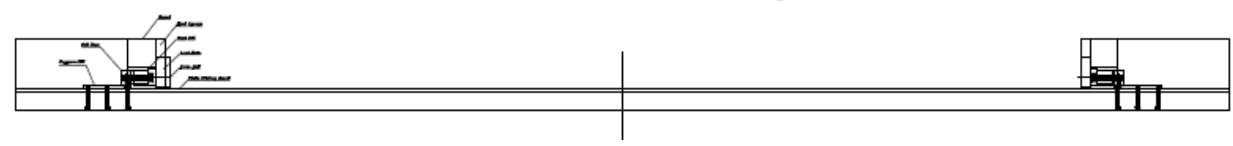

Fig.1. Schematic design of a whole force measurement system including a force sensing unit, skate sliding board, safety bars, and indicator.

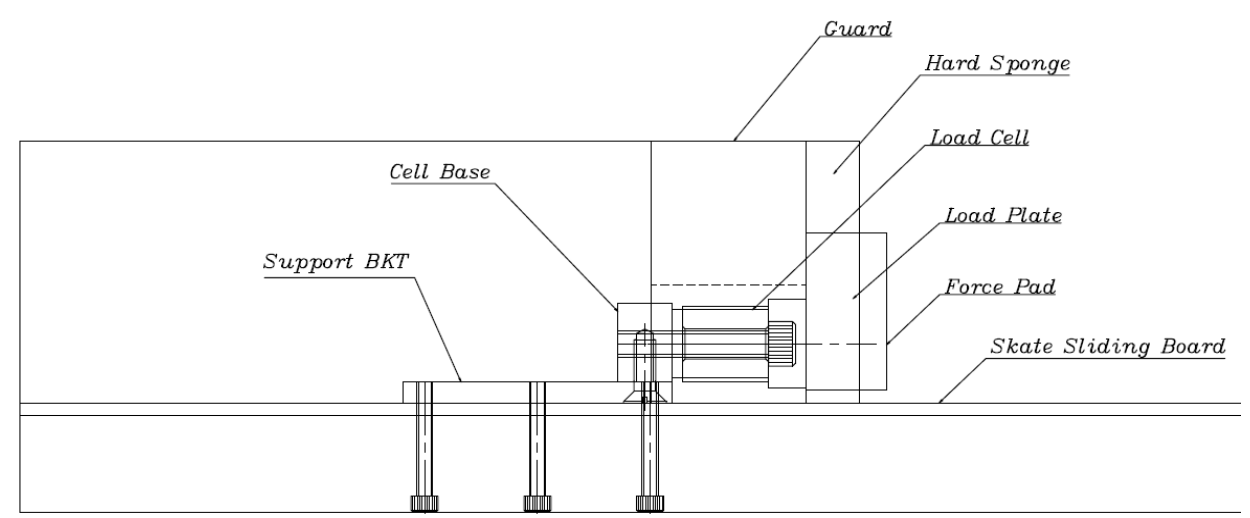

Fig.2. Schematic design of the force sensing unit with load cell. 


\section{Calibration}

The developed force measurement system was calibrated based on the standard calibration procedure of electric force measuring devices (c-07-1-0040-2002) [5]. Used calibration setup is electric force measuring device, which has a capacity of $1.5 \mathrm{kN}$ and a force resolution of $0.1 \mathrm{~N}$. Prior to its calibration, pre-loading was performed more than 3 times up to the designated weight during 30 seconds, then the sensor was kept without weight for 2 minutes. The calibration was performed 2 minutes after pre-loading, and at each point of loading, the signal was measured 20 seconds after the stabilization of the load. Calibrations were performed in the order of first increasing $\left(0^{\circ}\right)$, second increasing $\left(0^{\circ}\right)$, increasing and decreasing $\left(120^{\circ}\right)$, and increasing and decreasing $\left(240^{\circ}\right)$. The output forces from developed system were measured every $150 \mathrm{~N}$ until $1.5 \mathrm{kN}$.

Fig. 3 shows the calibration results for the force sensing units. As a result, the uncertainty of the force sensing unit on the left is within $0.087 \%$ and the uncertainty of the force sensing unit on the right is within $0.109 \%$. This relative expanded uncertainty includes repeatability error, rotation error, hysteresis error, interpolation error, and force standard measuring device error. It is also estimated that reliable measuring results can be obtained. This relative expanded uncertainty is reliable enough to make it possible to measure a lower-body muscular strength of skaters.

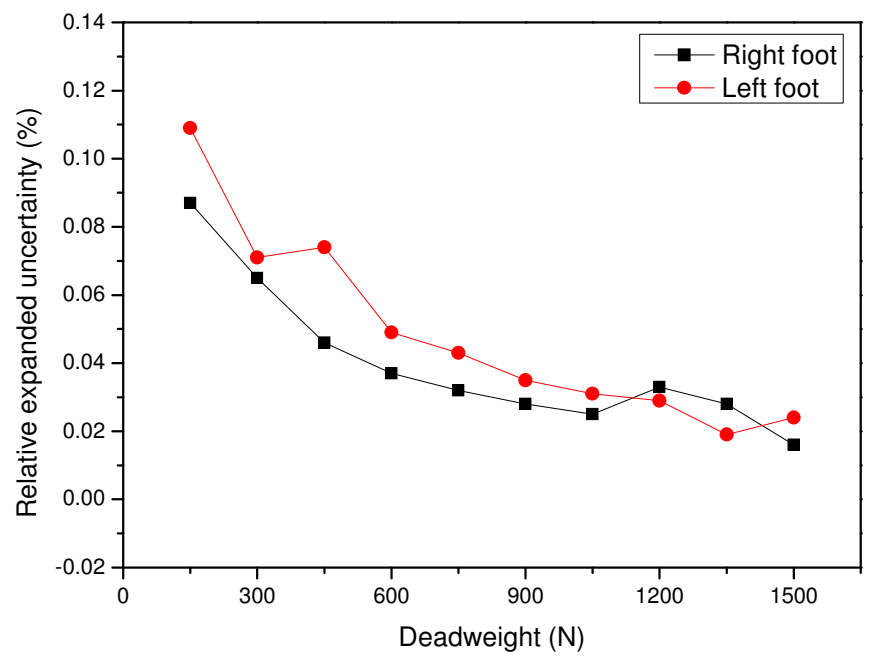

Fig.3. A calibration results for the force sensing units (Deadweight-relative expanded uncertainty graph).

\section{Evaluation and Results}

Fig. 4 describes a system configuration diagram of the developed force measurement system. As the shown Fig. 4, electrical signal were generated when the lateral pushing forces were applied to the left and right load cells. The electrical signals were transmitted 
to the load cell amplifier and then amplified. Noise of the amplified signals were reduced though noise filter. Then, the signals were transmitted to the PC. In order to check the feasibility of the developed force measurement system, a kinematic analysis is conducted with skater. Fig. 5 is the photograph of the fabricated force measurement system with skater. When the lower body training or the strength measurement, the rubbing wax was coated on the slide board before training or measurement in order to reduce friction. Then, the applying forces were obtained eleven times repeatedly from both left and right sides. At this time, the strengths of the quadriceps femoris muscles were measured as the major strength. LabVIEW ${ }^{\mathrm{TM}}$ was used to obtain data from the sensor system and analyze the data. We can derive the maximum values and the average values through LabVIEW $^{\mathrm{TM}}$ program.

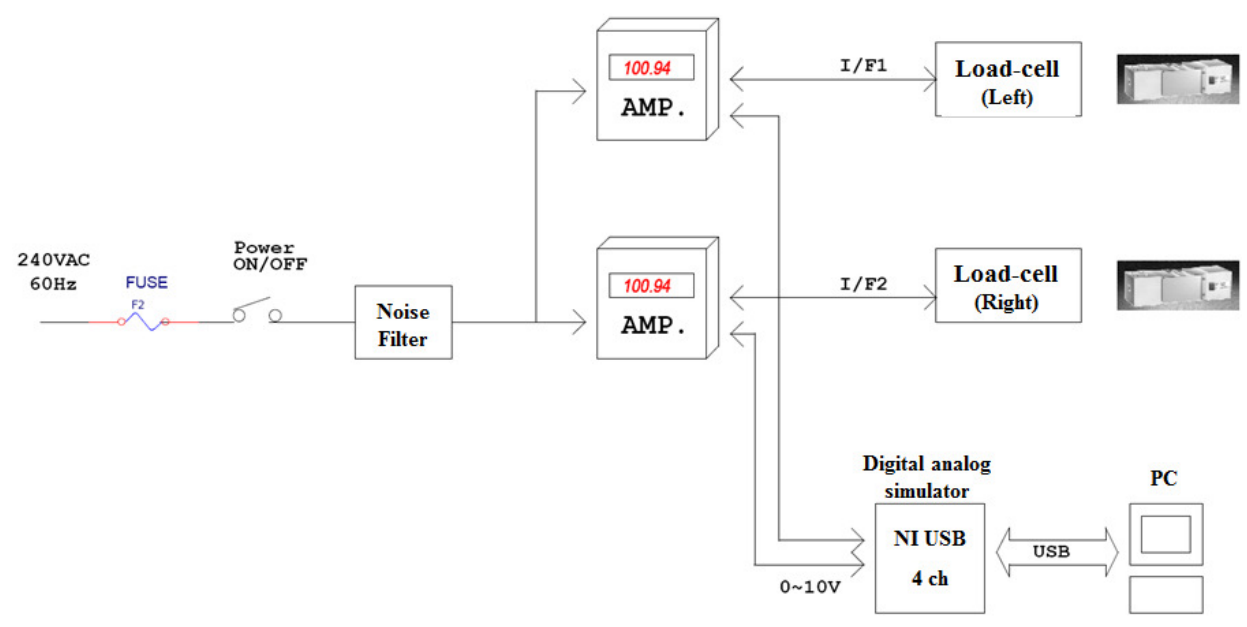

Fig.4. Configuration diagram of the developed force measurement system.

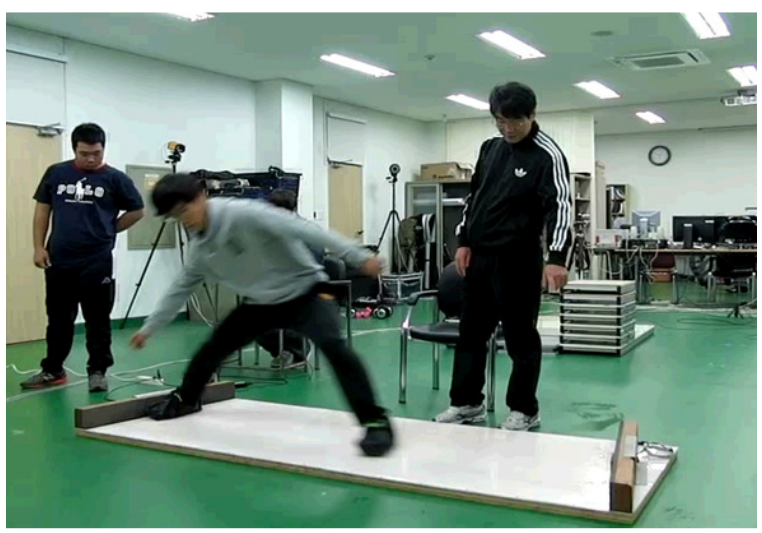

Fig.5. Photograph of lower body strength evaluation with fabricated system. 


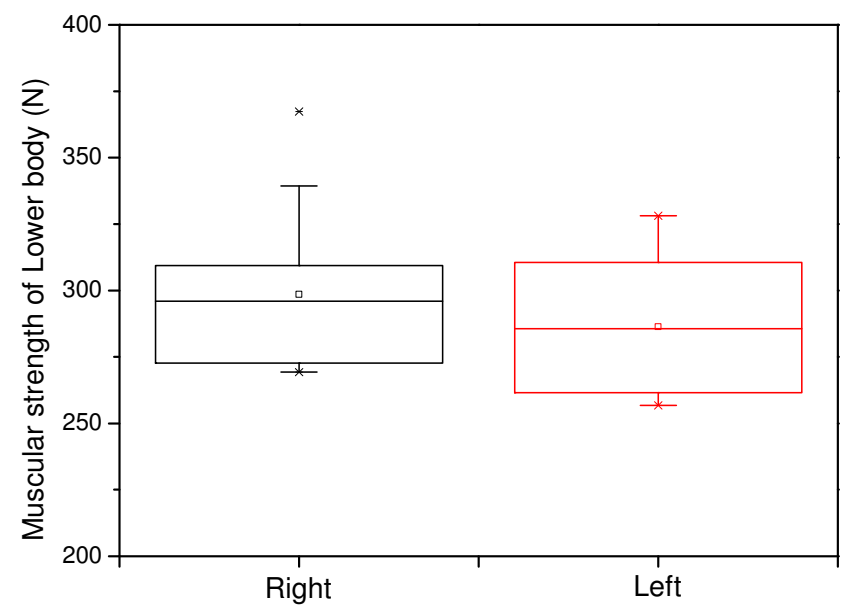

Fig.6. Results of the lower body strength evaluation with respect to both left and right foot.

Fig. 5 shows the results of the lower body strength evaluation. As a result, the maximum muscular strength of lower body on the right was $367.3 \mathrm{~N}$ and the minimum strength was $269.3 \mathrm{~N}$, while the maximum muscular strength of lower body on the left was $328.2 \mathrm{~N}$ and the minimum strength was $256.7 \mathrm{~N}$. The average strength of the lower body on the right was $298.5 \mathrm{~N}$ and the standard deviation was $31.08 \mathrm{~N}$, while the average strength on the left was $286.4 \mathrm{~N}$ and the standard deviation was $25.73 \mathrm{~N}$. This subject shows the deviation of left and right of $12.1 \mathrm{~N}$ with respect to average strength and $39.1 \mathrm{~N}$ with respect to the maximum strength.

This evaluation results are reliable enough to make it possible to measure a lowerbody muscular strength of skaters. The use of this measurement system will be expected to correct the posture of skaters and record the sports dynamics data for each athlete. It is believed that through the development of this equipment, skaters in elementary, middle, high schools, colleges, and the professional level have the systematic training to compete with world-class skaters.

\section{Conclusions}

The purpose of this study was to develop the force measurement system for measuring the force of the left and right low body when training speed skating. The system is constructed with a skate sliding board, a couple of sensor-units with load cell, indicator and control box, guard, force pad, and support bracket. The developed force measurement system was calibrated by the electric force measuring device, which has a capacity of $1.5 \mathrm{kN}$ and a force resolution of $0.1 \mathrm{~N}$. As a result, the uncertainty of the force sensing unit on the left is within $0.087 \%$ and the uncertainty of the force sensing unit on the right is within $0.109 \%$. This relative expanded uncertainty is reliable enough to make it possible to measure a lower-body muscular strength of skaters. In order to check the 
feasibility of the developed force measurement system, a kinematic analysis is conducted with skater. As a result, the subject shows the deviation of left and right of $12.1 \mathrm{~N}$ with respect to average strength and $39.1 \mathrm{~N}$ with respect to the maximum strength. This evaluation results are reliable enough to make it possible to measure a lower-body muscular strength of skaters. The use of this measurement system will be expected to correct the posture of skaters and record the sports dynamics data for each athlete. It is believed that through the development of this equipment, skaters in elementary, middle, high schools, colleges, and the professional level have the systematic training to compete with world-class skaters.

\section{References}

1. Ingen Schenau, G. J. van, and Bakker, K, A biomechanical model of speed skating, J. Human Movement studies. (1980).

2. Louis Keppler, Exercising apparatus for skaters, US Patent No. 4779862 A, June 29, (1987).

3. Louis Keppler, Exercise apparatus, US Patent No. 5114387 A, Febrary 22, (1991).

4. H. K. Kim and K. S. Ryu, Comparative Analysis on the Asymmetry of Speed Skater's Locomotion, Journal of Korea Society of Sports Science, Vol. 13, no. 2, pp. 827-838, (2004).

5. KRISS, Standard Calibration Procedure of Electric Force Measuring Devices (c-07-1-00402012), KRISS, (2012). 